\title{
Von Ehre, Schande und kleinen Verbrechen unter Nachbarn: Konfliktbewältigung und Götterjustiz in Gemeinden des antiken Anatolien
}

ANGELOS CHANIOTIS

L'ira tua formidabile e pronta colga l'empio, o fatal punitor (Verdi, Macbeth, 1. Akt, Finale)

\section{Theodikie in der antiken Mentalität}

Im späten 5. Jh. präsentierte der Sophist Kritias in seinem Satyrspiel Sisyphos folgendes Szenario von der Entstehung des Glaubens an die Götter. Am Anfang lebten die Menschen wie Tiere, ungeordnet und dem Stärksten untertan. Weder wurden die Tugendhaften belohnt noch die Bösen bestraft. Dann vereinbarten sie Gesetze, die offene Gewalttaten ahndeten, aber geheime Verbrechen nicht verhinderten. Um auch die heimlichen Übeltäter abzuschrecken, erfand ein Schlauer die Götterfurcht. Er führte göttliche Mächte ein, die alles sahen und hörten. Zur besseren Wirkung ließ er seine Phantasiegötter im Himmel wohnen, weil die Menschen über Himmelserscheinungen wie Blitz und Donner erschraken und sich über andere nützliche wie Sonne und Regen freuten. ${ }^{1}$

Nicht so viele griechische Denker gingen so weit und instrumentalisierten die Religion, indem sie die Entstehung des Götterglaubens mit der Hoffnung einer effektiveren Durchsetzung von Recht und Ordnung in Verbindung brachten. Zahlreicher waren jene, wie Diagoras von Melos, die einfach ihren Glauben verloren, weil sie beobachteten, wie viele Verbrecher unbestraft blieben. ${ }^{2}$ Babrius erzählt die witzige Geschichte eines Bauern, der resigniert beobachtete, dass die Götter nicht einmal jene bestrafen können, die ihr eigenes Vermögen rauben. Dieser Bauer verlor nämlich ein Werkzeug und verdächtigte andere Landarbeiter des Diebstahls. Als sie ihre Unschuld beteuerten, brachte er sie alle zur Stadt, um sie zu vereidigen - eine verbreitete Praxis in einer Zeit, die Fingerabdrücke, DNA-Analysen und andere Ermittlungsme-

\footnotetext{
1 Zitiert von Sextus, Mathem.9.54 (TragGrFr p. 771-773 ed. Nauck).

${ }^{2}$ Suda, s.v. Diagoras.
} 
thoden nicht kannte. Als sie alle die Stadt betraten, hörten sie einen Herold, der laut eine Belohnung in Höhe von 1000 Drachmen für jenen versprach, der Informationen über den Dieb geben konnte, der Wertsachen aus Apollons Heiligtum gestohlen hatte. Als der Bauer dies hörte, realisierte er, dass, wenn der Gott nicht einmal wusste, wer seinen eigenen Tempel beraubt hatte, er auch den Dieb seines Werkzeugs nicht ermitteln würde. ${ }^{3}$

Weder Kritik noch Verzweiflung zerstörten jedoch den Glauben, dass die Götter Verbrechen und Ungerechtigkeit ahnden. Dass ein ungerechter Mensch zu seinen Lebzeiten unbestraft bleiben kann, war und bleibt eine universelle Erfahrung. Aber dann konnte die Hoffnung, dass ihn im Leben nach dem Tod seine gerechte Strafe erwartet, die Frustration der Gerechten vermindern, auch wenn dies die Ungerechten nicht unbedingt entmutigte. Bereits die frühesten Zeugnisse über die Jenseitsvorstellungen kolonisieren die Unterwelt mit sündigen Menschen, deren Bestrafung ein Exemplum statuieren sollte. ${ }^{4}$ Ein gewisser Sinn für Gerechtigkeit konnte auch durch die Idee befriedigt werden, dass im Falle des Ausbleibens einer Bestrafung für einen Straftäter zumindest dessen Verwandte für seine Taten bezahlen mussten. ${ }^{5}$ Die kollektive Haftung ist keineswegs beschränkt auf die Blutrache im archaischen Griechenland, die erbliche Schuld in der Tragödie oder die rächenden Dämonen im Volksglauben. Wir begegnen ihr noch in öffentlichen Dokumenten der klassischen Zeit, z. B. im attischen Gesetz gegen die Tyrannen. ${ }^{6}$ Noch im frühen 3. Jh. v. Chr. fragte die Stadt Dodona das dortige Orakel des Zeus danach, „ob der Gott das Gewitter wegen der Unreinheit irgendeines Menschen bringt".?

Die Idee der Theodikie war in der antiken Mentalität fest verankert. Einem besonderen Aspekt ist dieser Aufsatz gewidmet, nämlich dem Glauben an das Eingreifen und der Mitwirkung der Götter in Konflikten des täglichen Rechtes.

\section{Epigraphische Zeugnisse zur antiken Theodikie}

Kleinasien stellt den geographischen Raum dieser Untersuchung dar. Die zeitliche Betrachtung erstreckt sich über die ersten drei Jahrhunderte nach Christus. Aus Kleinasien fehlen uns Papyri und somit auch eine grundlegende Quelle für die Konflikte und Delikte des Alltags. Dafür haben wir aber ein reiches epigraphisches Material, das nicht nur das Leben in den großen Städten wie Milet und Ephesos, sondern auch in den kleinsten Dörfchen beleuchtet.

\footnotetext{
${ }^{3}$ Babrius, fab. 2.; vgl. Versnel 1991, 78.

${ }^{4}$ Sourvinou-Inwood $1995,70$.

${ }^{5}$ Lloyd-Jones 1983, 35, 9of.; Parker 1983, 198-205; Burkert 1996, 108-113.

6 Aristoteles, Athenaion Politeia 16.10, Demosthenes 23.62.

7 Supplementum Epigraphicum Graecum XIX 427.
} 
Eine für die Konflikte des Alltags besonders wichtige Gruppe von Zeugnissen sind die in Lydien und Phrygien gefundenen „Beicht-“ oder „Sühneinschriften ". ${ }^{8}$ Es handelt sich um eine Gruppe von ca. 150 Inschriften, die ursprünglich in Tempeln aufgestellt waren und Geständnisse verschiedener Vergehen enthalten. Das Geständnis wurde durch göttliche Bestrafung erzwungen, durch Tötung der Tiere, Erkrankung, Unglück oder Tod.

Die Mehrzahl der Sühneinschriften betreffen Sakrilegien, Verstöße gegen Reinheitsvorschriften, Verletzungen des Eigentums der Tempel, Beleidigungen der Götter - also Konflikte zwischen Menschen und Göttern. Es gibt jedoch ca. 40 Texte, die auch Delikte des profanen Strafrechtes betreffen: Diebstahl, Ehebruch, versäumte Rückzahlung von Schulden an Privatpersonen oder an den Tempel, Beleidigung, Vergiftung, Magie oder Mitwisserschaft eines Verbrechens. Im Grenzbereich zwischen sakralem und profanem Delikt liegt der Meineid. ${ }^{9}$

Aus den längeren Texten wird deutlich, dass eine Person, wenn sie absichtlich oder unabsichtlich ein Vergehen beging oder eine Norm verletzte und dachte, dass die Götter sie dafür verfolgten, den Tempel aufsuchte und um Hilfe bat. Durch Orakel, göttliche Boten, Träume und Visionen offenbarte der Gott den Grund seines Zorns und teilte mit, wie die Wiedergutmachung erreicht werden konnte. Nur wenige Texte stellen jedoch die Ereignisse in ihrer chronologischen Reihenfolge dar. Kürzungen und schwerfällige Formulierungen erschweren oft das Verständnis. Ein Beispiel unter vielen betrifft einen Konflikt zwischen einer Frau und der Tempelverwaltung (Lydien, 118 n. Chr.): ${ }^{10}$

„Trophime, Tochter des Artemidoros, des sogenannten Kikinnas, wurde vom Gott zu einem Dienst aufgefordert, wollte aber nicht geschwind kommen; aus diesem Grund bestrafte sie der Gott und machte sie wahnsinnig. Sie fragte nun Meter Tarsene (,die göttliche Mutter von Tarsos ${ }^{\text {c) }}$ und Apollon Tarsios und Mes Artemidorou Axiottenos (d.h. den Mondgott Mes von Axiotta, dessen Kult von einem Artemidoros gestiftet worden war), der Koresa beherrscht. Und der Gott befahl mir, mich für den Götterdienst einzuschreiben“"

In der Mehrzahl der Texte erscheint der Sachverhalt Sünde - Bestrafung Wiedergutmachung als eine Angelegenheit zwischen Menschen und Gott, ohne Einschaltung anderer Instanzen. Die Dinge sind jedoch wesentlich komplexer. Das Eingreifen von Priestern kann in vielen Texten erkannt werden, und zwar auch in den Texten, die Konflikte unter Menschen und nicht zwischen Menschen und Göttern betreffen. In vielen Beichtinschriften - so auch im gerade zitierten Text - beobachten wir einen Subjektwechsel von der ersten zur dritten Person („Trophime wurde aufgefordert ...; der Gott befahl

\footnotetext{
${ }^{8}$ Von der sehr umfangreichen Bibliographie zitiere ich nur einige der jüngsten Untersuchungen, in denen weitere Literatur zu finden ist: Petzl 1994, 1997 und 1998; Ricl 1995 und 1997; Klauck 1996; Chaniotis 1997 und 2004 .

9 Chaniotis 1997.

${ }^{10}$ Petzl 1994, Nr. 57.
} 
mir ..."). Dies ist wohl darauf zurückzuführen, dass die Beichten - vor allem jene von Personen, die längere Texte nicht schreiben konnten - von Priestern niedergeschrieben wurden. Darüber hinaus waren die Priester jene, die die Befehle der Götter deuteten und vermittelten.

Die Rolle der Priester wurde in der Forschung kontrovers diskutiert. So hat Joseph Zingerle vor achtzig Jahren die These vertreten, dass in den Tempeln Prozesse in profanen Angelegenheiten stattfanden, ja, dass die Priester keine Hemmungen hatten, den Göttern beim Vollzug der Todesstrafe etwas nachzuhelfen. ${ }^{11}$ Diese Thesen ließen sich aufgrund des damals bekannten Materials nicht beweisen und fanden in der Forschung wenig Resonanz; Georg Petzl, Verfasser eines Corpus der Beichtinschriften schloss allerdings nicht aus, dass Priester als Richter fungierten (s. u. \$3). ${ }^{12}$ Eger bemerkte, dass es keine Hinweise auf Prozesse in den Tempeln gibt. Auf der anderen Seite vermutete er, dass Klagen von Personen, denen Unrecht angetan worden war, an die Priester eingereicht wurden und dass die Priester die Schuldigen (oder bloß Angeklagten oder Verdächtigten) verfluchten, die Zeichen des göttlichen Willens deuteten und die Konfliktparteien berieten. ${ }^{13}$ Marijane Ricl, Verfasserin eines Corpus dieser Texte, kam zu dem Ergebnis, dass die Priester nicht aus eigener Initiative handelten, sondern durch die Opfer von rechtswidrigen Taten dazu aufgefordert wurden einzugreifen. Ihre Tätigkeit bestand darin, die Konfliktparteien zu vereidigen und die bekannten oder unbekannten Täter zu verfluchen. ${ }^{14}$ Meine eigenen Untersuchungen haben die Ansichten von Eger und Ricl bestätigt. ${ }^{15}$ In dieser Arbeit geht es nicht um die Rekonstruktion der in diesen Heiligtümern durchgeführten Rituale und Verfahren, sondern um die Bedeutung der Beichtinschriften als Zeugnisse für die Konflikte des Alltags und deren Bewältigung.

Diese Texte versteht man besser, wenn man sie nicht isoliert betrachtet, sondern in einem Zusammenhang mit einer Gruppe magischer Texte (Fluchinschriften), die Henk Versnel sehr treffend als "Gebete für Gerechtigkeit “ bezeichnet hat. ${ }^{16}$ Solche Texte kennen wir beispielsweise aus Knidos (2.-1. Jh. v. Chr.). Im dortigen Heiligtum der Demeter kamen Texte zu Tage, in denen Frauen Personen verfluchen, indem sie den dort verehrten Göttern „weihen“, d. h. sie der göttlichen Strafe überlassen. Ein Beispiel: ${ }^{17}$

„Ich weihe an Demeter und Kore den Verleumder, der behauptet hat, dass ich ein Gift gegen meinen eigenen Mann zubereitet habe. Ich wünsche mir, dass er zusammen mit seiner ganzen Familie brennend zum Heiligtum der Demeter kommt und dort ein Geständnis macht“.

\footnotetext{
11 Zingerle 1926.

12 Petzl 1988 und 1994, 8-11.

13 Eger 1939.

14 Ricl 1995.

15 Chaniotis 1997 und 2004.

16 Versnel 1991, 68-75, 81-93; 1999, 127; 2002, 48-50.

17 Blümel 1992, Nr. 150; für den vollständigen Text s. u. S. 249.
} 
Was in diesem Text auffällt, ist die Bedeutung von Ehre und Schande: Verleumdung ist das Unrecht, das dieser Frau angetan worden war. Ferner fällt der Wunsch auf, dass der Schuldige seine Schuld öffentlich gesteht. Die verletzte Ehre der Frau wird nur durch den Ehrverlust ihres Verleumders wiederhergestellt. Die Verletzung der Ehre und die Rolle der Öffentlichkeit sind Leitmotive der folgenden Seiten.

Solche Gebete für Gerechtigkeit sind weit verbreitet; wir finden sie von Kleinasien bis Britannien. Sie sind eng verwandt mit Gelübden von Personen, die die Götter um Hilfe in verschiedenen Angelegenheiten des Alltags bitten, darunter auch um Unterstützung in rechtlichen Konflikten und in finanziellen Angelegenheiten; so etwa das Gelübde einer Frau: Sie „machte ein Gelübde bei Mes Axiottenos: ,Wenn ich die Anteile von der Mutter erhalte'. Nachdem ich sie erhalten habe, weihte ich die Stele für die Dinge, wofür ich das Gelübde gemacht hatte ${ }^{\text {“18 }}$ Ein nicht erfüllter Wunsch konnte das Gefühl von Ungerechtigkeit und von Ehrverlust verstärken.

Die Idee, dass Straftaten von den Göttern verfolgt werden, kommt schließlich bei einer weiteren Gattung von Inschriften vor, bei denen wir sie eigentlich nicht unbedingt erwarten: bei Grabinschriften. Einige Texte fordern die Götter auf, ein bestimmtes Vergehen (Mord, Vergiftung, Diebstahl) zu verfolgen oder Rache zu nehmen, da der Verstorbene nicht mehr dazu in der Lage war. Ein Beispiel finden wir in einer Inschrift aus Daskyleion. ${ }^{19}$ Ein Ehepaar stellte eine Grabstele mit der Darstellung von gehobenen Händen (Gestus der Fürbitte) auf und forderte Rache für den Tod ihres Sklaven; der Sklave war vor seiner Zeit, also unerklärlich und unnatürlich gestorben (sie „... weihten diese Stele für den vor seiner Zeit verstorbenen Sklaven, indem sie die Sonne und alle Götter als Zeugen anrufen, damit sie für uns Rache nehmen"). ${ }^{20}$ In diesem konkreten Fall wurzelt der Rachegedanke in der Frustration, die aus der Unfähigkeit entsteht, den für ein Unrecht Verantwortlichen zu identifizieren und zu bestrafen. Sehr häufig ist er aber vor dem Hintergrund von Ehrverletzung und Gesichtsverlust zu sehen.

\section{Priester als Schlichter in Konflikten zwischen Göttern und Sterblichen}

Eine Beichtinschrift aus Lydien schildert uns eine für die unter den wachsamen Augen der Götter lebenden Gemeinden Anatoliens charakteristische Konfliktsituation (191 n. Chr.): ${ }^{21}$

\footnotetext{
${ }^{18}$ Supplementum Epigraphicum Graecum XLI 1012 Z. 4-10.

19 Supplementum Epigraphicum Graecum XLIV 1050 Z. 3-11.

${ }^{20}$ Weitere Beispiele in Chaniotis 2004, 9-10.

${ }^{21}$ Petzl 1994, Nr. 36.
} 
„Für Mes Labanas. Elpis hat den Mes Labanas verachtet; sie bestieg sein Podium ohne vorherige Waschung und untersuchte seine Tabletts (Holztafeln mit Texten?). Nachdem der Gott sie verfolgt hatte, erstatteten die Erben (die Wiedergutmachung, d. h. die Inschrift), indem sie ihn preisen. Im 276. Jahr, im Monat Peritios. - Lobend erstatten wir die Stele auch dem Mes Axiottenos. - ,Mein Podium hat sie besudelt ${ }^{\text {, }, . ~}$

Elpis hatte eine Reinheitsvorschrift verletzt und dies mit ihrem Leben bezahlt. Die Härte der Strafe, die auf den ersten Blick in keinem Verhältnis zum Vergehen steht, erklärt sich aus der Bedeutung der Normen für den Zusammenhalt kleiner dörflicher Gemeinden. Die letzten Worte des Textes zitieren den Orakelspruch des Gottes, der den Grund seines Zorns erklärt. Die Wiedergutmachung erfolgte durch die Aufstellung der Inschrift.

Im Lichte solcher Texte kann man die Rolle der Priester in diesen Orten verstehen. Sie waren Deuter der Götterjustiz. Sie gaben den kleinen und großen Tragödien des Alltags Sinn, indem sie diese als Strafe der Götter darstellten. Wenn eine Person zum Heiligtum kam, krank, verzweifelt, verarmt, verwaist, von Unglück verfolgt, um sich nach dem Willen der Götter zu erkundigen und zu erfahren, wie sie dem Unglück ein Ende setzen könnte, waren die Priester bereit zu helfen. Während der Gespräche versuchten sie, die mögliche Ursache des göttlichen Zorns zu ermitteln. Und so wie die menschliche Natur sich darstellt, ist es zweifelhaft, ob es ihnen schwer fiel, eine Unrechtstat zu finden. Da ihre Klienten in der Nähe der Heiligtümer lebten, waren Verletzungen religiöser Normen unvermeidlich. Ein Kind warf beispielsweise eine Weihung im Heiligtum um, ein anderes betrat das Heiligtum mit beflecktem Kleid. ${ }^{22}$ Und wenn der verzweifelte Klient gar keine Ahnung hatte, wie er den Zorn der Götter provoziert hatte, bestand immer die Möglichkeit, dass er für die Verfehlungen eines Verwandten oder der Vorfahren büßte. Und sollte die Familie seit Generationen Vorbild der Unschuld gewesen sein, wie konnte man ausschließen, dass eines ihrer Mitglieder etwas unabsichtlich oder unwissentlich verbrochen hatte? Auch hierfür hatten die Priester ein Rezept: die pauschale Entsühnung von Verfehlungen, „von denen man weiß (oder sich bewusst ist) und von denen man nicht weiß" (ex eidoton kai me eidoton). ${ }^{23}$

Ich brauche nicht zu erwähnen, dass sich das Leben auch weiterhin mit seinen kleinen Desastern fortsetzte. So kamen viele Personen zum Heiligtum zurück, nachdem sie festgestellt hatte, dass die erste Beichte nicht genug war. Einige hörten erst in ihrem Grab damit auf, ihre Sünden zu beichten. Einige appellierten an mildernde Umstände: „Ich habe es nicht gewusst“; „ich tat es unabsichtlich“. Ein Mann, der bestraft wurde, weil er das Keuschheitsgebot gebrochen hatte, entschuldigte sich: „Aber (ich schlief) mit meiner eigenen

\footnotetext{
${ }^{22}$ Petzl 1994, Nr. 78 und 55.

${ }^{23}$ Petzl 1994, 6of.; Ricl 1995, 68; Chaniotis 2004, 35.
} 
Frau“ ${ }^{24}$ Diese Entschuldigungen sind Bitten nicht um Milderung der ohnehin bereits vollzogenen Strafe, sondern um eine leichtere Wiedergutmachung. Manchmal wurden diese Bitten erhört.

„Im 251. Jahr, am 2. des Monats Panemos. Die Götter haben dem Eudoxos gestattet, den Meineid für seine eigene Frau zu löschen, da [obwohl] die Eide der Tarsene nicht gelöscht werden. Weil Sardion einen falschen Eid geleistet hatte, aus diesem Grund, da sie noch nicht volljährig war, löschte Eudoxos die Meineide durch Zahlung von 9 Obolen, stellte eine Inschrift auf und dankt“.25

Auf der gleichen Inschrift wird die gültige Regelung zitiert: Für das Löschen eines Eides war der hohe Betrag von 175 Denaren zu zahlen; die mildernden Umstände - die meineidige Frau war minderjährig - erlaubten ihrem Mann, sich mit dem lächerlichen Betrag von 9 Obolen (etwas mehr als ein Tageslohn) mit den Göttern zu versöhnen.

Die Rolle der Priester war also die von Vermittlern in einer Konfliktsituation zwischen zornigen Göttern und sündigen Sterblichen. Diese Rolle ist auch im längsten relevanten Text zu erkennen, in einer Beichtinschrift, in der die Sünden, die Bestrafung und die Entsühnung eines gewissen Theodoros geschildert werden (Silandos, $235 \mathrm{n}$. Chr.). ${ }^{26} \mathrm{Im}$ Text werden abwechselnd die Geständnisse des Theodoros und die Orakel eines Gottes (Mes eher als Zeus) zitiert, die sich auf die Entsühnung beziehen. Theodoros, ein Tempelsklave, verstieß wiederholt gegen das Verbot des Geschlechtsverkehrs und beging sogar Ehebruch mit einer verheirateten Sklavin. Er wurde blind und suchte den Tempel auf. Durch Orakel klagte ihn der Gott an und begründete die Strafe. Nach Geständnis seiner Vergehen führte Theodoros ein Sühneritual durch. Der Gott wurde dann nach seinem Rat gefragt und begnadigte den Theodoros:

Theod.: Weil ich von den Göttern zur Vernunft gebracht wurde, von Zeus und vom Großen Mes Artemidorou, (habe ich die Inschrift aufgestellt).

Gott: Ich habe Theodoros an seinen Augen für die Verfehlungen bestraft, deren er sich schuldig gemacht hatte.

Theod.: Ich hatte Geschlechtsverkehr mit Trophime, der Sklavin des Haplokomas und Frau des Eutychis, im Praetorium.

Gott: Er nimmt die erste Verfehlung mit einem Schaf, einem Rebhuhn, einem Maulwurf weg. Zweite Verfehlung.

Theod.: Als ich Sklave der Götter von Nonnos war, hatte ich Geschlechtsverkehr mit der Flötenspielerin Ariagne.

Gott: Er nimmt weg mit einem Choiros [Flussfisch oder Ferkel?], einem Thunfisch, einem Fisch.

Theod.: Bei der dritten Verfehlung hatte ich Geschlechtsverkehr mit der Flötenspielerin Aretousa.

\footnotetext{
${ }^{24}$ Chaniotis 1997, 36of.; z. B. Petzl 1994, Nr. 55, 58, 68, 78, 111 .

${ }^{25}$ Petzl 1994, Nr. 58.

${ }^{26}$ Petzl 1994, Nr. 5; Ricl 1995, 72f.; Chaniotis 1997, 357-360 und 2004, 27-30.
} 
Gott: Er nimmt weg mit einem Huhn, einem Spatz, einer Taube. Ein Kypros [Messeinheit] Getreide und Gerste, ein Prochus Wein, ein Kypros reiner Gerste für die Tempeldiener, ein Prochus.

Theod: Ich hatte Zeus als meinen Rechtsbeistand.

Gott: Ich habe ihn geblendet für seine Taten. Da er aber jetzt die Götter gnädig stimmte, nehmen sie seine Sünden weg. Gefragt vom, Senat' (synkletos) bin ich ihm gnädig, wenn meine Stele errichtet wird, an dem Tag, den ich bestimmt habe. Du sollst das Gefängnis öffnen. Ich lasse den Gefangenen frei, nach einem Jahr und 10 Monaten.

Auf den ersten Blick scheint uns so etwas wie das Protokoll einer Gerichtsverhandlung vorzuliegen. Nach Georg Petzl fand tatsächlich ein Prozess im Tempel statt, Theodoros wurde verurteilt und in den Kerker geworfen. Nach Ender Varinlioğlu ist der Gebrauch des Wortes Gefängnis (phylake) symbolisch zu verstehen; ${ }^{27}$ die Blindheit des Theodoros sei die Strafe, durch welche ihm die Götter seine zügellosen sexuellen Aktivitäten einschränkten. Ein neuer (noch unveröffentlichter) Text hat die Frage beantwortet: Er erwähnt einen "Senat der Götter" (synkletos theon); der Prozess fand also im Himmel, nicht im Tempel statt. Das Heiligtum hatte nicht als Gerichtshof fungiert, sondern die Priester hatten die Orakelsprüche des Gottes vermittelt und Rat gegeben, wie der göttlichen Strafe ein Ende gesetzt werden konnte.

In der Beichte des Theodoros geht es um einen Konflikt zwischen einem Sterblichen und den Göttern, der unter Vermittlung der Priester beigelegt wird. Es stellt sich nun die Frage, ob und wie die Priester im Auftrag der Götter auch in Konflikten des täglichen Rechtes eingriffen.

\section{Alltagskonflikte und Götterjustiz}

Ein typischer Konflikt in einer kleinen dörflichen Gemeinde ist der Streit um entlaufene Tiere (Kula, 114 n. Chr.): ${ }^{28}$

„Groß ist (göttliche) Mutter Anaitis, die Herrscherin von Azita, und Mes Tiamou und ihre Macht. (Angelegenheit des) Hermogenes und Apollonios, Sohn des Apollonios, des sogenannten Midas, aus dem Ort Syrou Mandrai. Drei Schweine des Demainetos und des Papias aus Azita irrten umher und mischten sich mit den Schafen des Hermogenes und des Apollonios - ihr fünfjähriger Sklave hütete sie. Diese führten die Schweine weg. Als nun Demainetos und Papias die Schweine forderten, gestanden Hermogenes und Apollonios (dies) nicht, aus irgendeiner Ungefälligkeit ...."

Wären die Tiere irgendwie (z. B. mit einem Stempel) als Eigentum des Demainetos und des Papias gekennzeichnet, so wäre der Streit von den profanen Behörden des Dorfes leicht beizulegen; dies war hier offenbar nicht der Fall. In dieser Konfliktsituation wandten sich nun die beiden Männer, genau wie

\footnotetext{
27 Varinlioğlu 1989, 37-39.

28 Petzl 1994, Nr. 68.
} 
der Bauer in Babrius' Fabel, an das lokale Heiligtum. Sie nahmen keine Vereidigung ihrer Gegner vor, sondern sie verfluchten sie:

„... Und nun ist das Szepter der Göttin und des Herren des Tiamos, aufgestellt worden ...“

Der Ausdruck „das Szepter aufstellen “ kommt in einigen Varianten in den Inschriften Lydiens vor und bezieht sich auf die Aufstellung des Symbols der göttlichen Macht in einem Heiligtum anlässlich einer Verfluchung. ${ }^{29}$ Die Aufstellung des Szepters hatte eine doppelte Funktion: künftige Straftaten zu verhindern (s. u. S. 248) und Straftäter zu informieren, dass sie früher oder später - und wenn nicht sie, dann ihre Familie, ihre Tiere, ihre Habe - Opfer des göttlichen Zorns würden. Das Vergehen wurde der Götterjustiz übergeben.

„... und da sie (immer noch) nicht gestanden, zeigte die Göttin ihre Macht. Und nachdem die Gattin des Hermogenes und sein Kind und auch Apollonios, der Bruder des Hermogenes, gestorben waren, sühnten sie die Götter. Und nun bezeugen wir ihre Macht und preisen sie zusammen mit den Kindern. Im 199. Jahr“.

Auch nach der Verfluchung weigerten sich Hermogenes und Apollonios, die Tiere zurückzugeben, bis persönliche Schicksalsschläge, die als göttliche Strafe gedeutet wurden, sie dazu zwangen. Wichtig ist hier die Erwähnung einer wiederholten Weigerung; sie kann nur vor den Priestern geäußert worden sein, denn die Kläger hatten ja ihre Forderung schon einmal vergeblich gestellt.

Ein Text aus Ayazvoran betrifft einen ähnlichen Fall (3. Jh. n. Chr.). In einem Rechtsstreit über Schafe wurde das Urteil gefällt, der Kläger müsse durch Eid die Richtigkeit seiner Behauptungen bekräftigen: ${ }^{30}$

„[Lücke] - Hermogenes Valerios, Sohn des Apollonios, hatte sich dem Kaikos und Tryphon für deren Kleinvieh eingesetzt. Es wurde das Urteil gefällt, Hermogenes solle einen Eid leisten, er habe seine Pflicht gegenüber den Schafen nicht vernachlässigt. Ohne Kenntnis (des Sachverhaltes? oder ohne Kenntnis der Macht der Götter) schwor Hermogenes beim Gott .....

Der Eid war ein falscher und der Meineidige wurde durch Tötung seines Rindes und seines Esels bestraft - richtiger: weil er von Unglück verfolgt wurde, dachten alle, dass er einen Meineid geleistet hatte. Trotz dieser Schäden beharrte der Mann auf seinem Eid - wir begegnen erneut der wiederholten Weigerung eines Geständnisses. Erst als auch seine Tochter starb, löschte er endlich den (Mein)eid, sicher durch Entrichtung der vorgesehenen Gebühr:

„... Der Gott zeigte die ihm eigene Machtfülle und bestrafte den Hermogenes und fügte ihm Schädigungen zu, indem er ihm sein Vieh tötete - einen Ochsen und einen Esel. Als Hermo-

\footnotetext{
${ }^{29}$ Robert 1983, 518-520; Strubbe 1991, 44f.; Petzl 1994, 4 und 89f.; Versnel 1991, 76, und 2002, 64; Ricl 1995, 69.

${ }^{30}$ Petzl 1994, Nr. 34 .
} 
genes im Ungehorsam verharrte, tötete er dessen Tochter. Da löste er den Schwur. Wir, Apphias und ihre Kinder, Alexandros, Attalos, Apollonios und Amion, haben die Stele errichtet und auf ihr die Manifestation der Macht des Gottes schriftlich festgehalten, und von jetzt ab lobpreisen wir ihn“"

Die Formulierung „seine Aussagen wurden von den Prozessgegnern überprüft" (also als falsch bloßgestellt) in einem sehr fragmentarischen Text bezieht sich sicher auf einen Meineid in einem Rechtsstreit. Die Mitwirkung von Priestern bei Vereidigungen ist ein in der griechischen und römischen Antike bekanntes Phänomen. Ein Volksbeschluss aus Pednelissos in Pisidien bezeugt die Mitwirkung des Kultpersonals bei Rechtskonflikten, und zwar im Zusammenhang mit Vereidigungen und Verfluchungen. Diese Handlungen fanden sicher im Heiligtum statt; so erklärt sich auch die gelegentlich bezeugte Zahlung von Gebühren an die Götter und ihre Priester. ${ }^{32}$

Am deutlichsten zeigt sich die Rolle der Heiligtümer im Zusammenhang mit der Beilegung von Konflikten in jenen Fällen, in denen das Opfer einer rechtswidrigen Tat den Täter nicht bei einer städtischen Behörde anzeigte, sondern zum Heiligtum ging, dort eine Klageschrift (pittakion) abgab und die Götter um Eingriff bat. Eine Beichtinschrift aus Silandos oder Saittai belegt dieses Verfahren. Es scheint, dass Hermogenes und Nitonis gegen Artemidoros falsche Anschuldigungen in Bezug auf Wein (bei einer Transaktion?) erhoben hatten. Artemidoros sah sich mit Gesichtsverlust konfrontiert. Seine Reaktion bestand darin, einen „Zettel“ (pittakion) an die Götter einzureichen, d. h. eine Schreibtafel mit einer Klageschrift den Priestern zu übergeben. Jedes Unglück, das seinen Beleidigern widerfahren würde, würde dann als göttliche Strafe verstanden. In der Tat wurde Hermogenes gezwungen, sich mit den Göttern zu versöhnen; ob er sich auch mit Artemidoros versöhnte, verrät uns der Text nicht, aber es ist davon auszugehen, dass mit dem öffentlichen Schuldbekenntnis der Konflikt beendet wurde: ${ }^{32}$

„Dem Mes Axiottenos. Weil Hermogenes, Sohn des Glykon, und Nitonis, Tochter des Philoxenos, Artemidoros beleidigten in Bezug auf den Wein, hat Artemidoros einen Zettel eingereicht. Der Gott hat Hermogenes bestraft, und er hat gesühnt, und von nun an führt er gute Gedanken“.

Die Sühne des Hermogenes setzt natürlich voraus, dass er von Artemidoros' Handlung, d. h. vom Deponieren der ,Klageschrift' wusste. Wie? Artemidoros selbst hat ihn vielleicht in Kenntnis gesetzt („Du wirst es mir teuer bezahlen ..."); oder Hermogenes war Zeuge einer öffentlichen Zeremonie gewesen; oder er wurde über die,Klageschrift' von den Priestern informiert, die sie erhalten hatten. So oder so richtete sich Artemidoros' Pittakion an die Öffentlichkeit. Es konnte gar nicht anders sein: Das Ziel war ja, die Ehre des Ar-

31 Sokolowski 1955, Nr. 79.
32 Petzl 1994, Nr. 60. 
temidoros zu retten. Auf die Rolle von Ehre, Schande und Öffentlichkeit werden wir noch zurückkommen.

Auch ein anderer Text, der nicht ausdrücklich das Einreichen eines Pittakion erwähnt, ist ähnlich zu verstehen: ${ }^{33}$

"Groß ist Mes Artemidorou, der über Axiotta herrscht, und seine Macht. Tatia, Tochter des Nikephoros, aus Mokada, hatte an Gaius und Apphia, seine Gattin, aus Mokada, Bronzegeld ausgeliehen, indem sie im voraus sagte, [eine Frist] ich leihe aus'. Gaius ließ nun seine Schulden ihr gegenüber unbezahlt. Da nun das Darlehen an Tatias nicht zurückgezahlt wurde, hat sie gegen ihn den Gott angerufen. Groß ist nun ..." (der Rest des Textes ist nicht erhalten).

Pfleger des Kultes dieser Götter, Deuter ihres Willens und Verfechter der Idee einer Theodikie waren die Priester, die sehr selten in den relevanten Texten zum Vorschein kommen. Nur indirekt können wir ihre Eingriffe erkennen: die Deutung der Orakel, der Versuch der Schlichtung, die Durchführung von Eideszeremonien und Verfluchungen. Diese Rolle ergab sich aus dem Glauben an die Theodikie. Ebenso wichtig war jedoch auch die Tatsache, dass in den dörflichen Gemeinden Kleinasiens die Heiligtümer die wichtigsten Orte des öffentlichen Lebens waren. Als Orte der Öffentlichkeit waren sie für die Beilegung von Konflikten, die mit Ehre, Schande und Gesichtsverlust (s. \$5) zu tun hatten, prädestiniert.

Die vorhin zitierten Texte gehen von der Voraussetzung aus, dass Götter in Konflikten des Alltags eingriffen und nicht als letzte, sondern als einzige Instanz die Konflikte beendeten. Man ist geneigt, von "göttlichen Urteilen“ und von einer Götterjustiz zu sprechen. In der Tat wird das Eingreifen der Gottheit in den Inschriften Anatoliens oft mit einem Strafprozess verglichen. Der Grabräuber wird mit Ausdrücken bedroht wie etwa „er soll gegenüber den Göttern einer Strafe verfallen sein“ (enochos esto theois), ,er soll von den unterirdischen Göttern gerichtet werden“ (dikas tinein) oder „er soll vom Gott gerichtet werden" (pros ton theon krisin echein). ${ }^{34}$

Bei genauer Betrachtung erkennt man jedoch, dass die Reaktion der Götter in einigen Fällen nicht jene von unbeteiligten, objektiven Richtern war, sondern die Rache von Geschädigten. Dies war das Ergebnis einer oft in antiken Fürbitten an die Götter angewandten Überzeugungsstrategie. Das Opfer von Unrecht versuchte manchmal nicht Mitleid, sondern den Zorn der Götter zu erwecken. Dies wurde dadurch erreicht, dass der Konflikt mit einem Sterblichen auf die Gottheit übertragen wurde, die Gottheit zum Geschädigten gemacht wurde. Wie diese Strategie funktionierte, zeigt uns eines der „Gebete für Gerechtigkeit" aus Lydien. Es handelt sich um eine $8 \times 5 \mathrm{~cm}$ große Bleitafel, die mit einem Nagel an einer Konstruktion (Wand, Tafel, Balken) befestigt war, wie aus einem kleinen Loch oben hervorgeht: ${ }^{35}$

\footnotetext{
${ }^{33}$ Petzl 1994, Nr. 79.

${ }^{34}$ Chaniotis $1997,360$.

${ }^{35}$ Supplementum Epigraphicum Graecum XXVIII 1568 und XI 1049; Versnel 1991, 74; 1999, 145; $2002,55$.
} 
„Ich weihe der Mutter der Götter alle goldenen Sachen, die ich verloren habe, damit sie sie sucht und alles offenbart und jene bestraft, die sie haben, gemäß ihrer eigenen Machtfülle, damit sie nicht belächelt wird“.

Der anonymen Frau ging es nicht um Rückerstattung der gestohlenen Sachen, sondern um Rache. Sie schenkte der Göttin die Wertsachen - was ihr eigentlich leicht fiel, da sie sie ohnehin nicht mehr besaß - in der Erwartung, dass die Göttin aktiv wurde und ihr (d.h. der Göttin) Vermögen zurückholte, damit sie (die Göttin) nicht lächerlich erschiene. Zusammen mit den gestohlenen Gegenständen wird auch der eigene Gesichtsverlust von der Frau auf die Göttin übertragen. Die Göttin sollte jetzt beleidigt sein und unter Handlungszwang stehen.

Diese Überzeugungsstrategie kennt man im Übrigen ebenfalls aus antiken magischen Texten. Ein magischer Papyrus empfiehlt beispielsweise, den Zorn einer Gottheit gegen eine Frau im Kontext von Liebeszauber dadurch zu erwecken, dass man die unwillige Frau der Verleumdung heiliger Riten beschuldigt: $^{36}$

„Ich gehe, zu melden die Verleumdung durch die verbrecherische und frevle NN; hat sie doch verleumderisch von deinen heiligen Geheimnissen geredet, den Menschen zur Kenntnis. Die NN ist es, die es gesagt hat - nicht ich bin es, die so sagte:, Ich sah, wie die größte Göttin das himmlische Gewölbe verließ und auf der Erde sandalenlos, Schwert tragend, einen unziemlichen Namen rief'. Die NN ist es, die sagte:, Ich sah die Göttin Blut trinken' usw.“

Die durch die Entweihung der heiligen Mysterien geschädigte und zornige Göttin soll dann im Sinne des Verfluchers handeln:

"Gehe zur NN und nimm von ihr den Schlaf und gib ihr Brand der Natur, Züchtigung ihrer Sinne und rasende Leidenschaft und vertreibe sie von jedem Ort und jedem Haus und führe sie zu mir, dem NN“.

Diese Überzeugungsstrategie, die Übertragung eines Konfliktes auf die Gottheit, erklärt, warum auch ein besonderes Zessionsverfahren angewandt wurde: Eine Konfliktpartei trat nämlich ihre Forderung (z. B. nicht zurückgezahlte Darlehen oder gestohlene Sachen) an die Götter ab, in der Hoffnung, dass die Götter die Forderung beim Schuldner oder Dieb geltend machen werden. ${ }^{37}$ So in einem Text aus Ayvatlar (118 n. Chr.). Apollonios hatte dem Skollos ein Darlehen in Höhe von 20 Denaren gegeben: ${ }^{38}$

„Als dann Apollonios das Geld von Skollos zurückforderte, leistete Skollos einen Eid gegenüber den vorher genannten Göttern (Mes Tiamou und Meter Atimis), dass er innerhalb einer Frist das zusammengekommene Kapital zurückgeben werde. Da aber Skollos das Versprechen nicht einhielt, trat Apollonios (seine Forderung) der Göttin ab. Nachdem nun

\footnotetext{
${ }^{36}$ Papyri Magicae Graecae IV 2471-9. Für diese Strategie s. Graf 1996, 163-166.

${ }^{37}$ Chaniot is 1997, 364f. und 2004, 16-19; vgl. Versnel 2002, 53f.

${ }^{38}$ Petzl 1994, Nr. 54; Chaniotis 2004, 16 f.
} 
Skollos durch den Tod bestraft wurde, stellten die Götter nach seinem Tod ihre Forderung. Seine Tochter Tatias löschte nun die Eide [d.h. bezahlte den geschuldeten Betrag] und jetzt, nachdem sie gesühnt hat, preist sie Meter Atimis und Mes Tiamou“.

Geschädigt durch die versäumte Rückzahlung war nun die Göttin, die vermutlich zum Schluss den geschuldeten Betrag erhielt. Der Gewinn von Apollonios war nicht von materiellem Wert, aber trotzdem nicht weniger wichtig: Rache.

\section{Gesichtsverlust als Konfliktursache}

Eine Beichtinschrift aus Kula ist für die Natur alltäglicher Konflikte aufschlussreich (156 n. Chr.). ${ }^{39}$ Im Dorf wurde das Gerücht verbreitet, Jucundus sei von seiner Schwiegermutter Tatias durch Gift (oder Zaubermittel) in den Wahnsinn getrieben worden. Die beschuldigte Frau verteidigte sich gegen diese Verleumdung, indem sie im Tempel, also öffentlich, ihre Verleumder verfluchte.

„Im 241. Jahr, am 2. Tag des Monats Panemos. Groß sind Artemis Anaitis und Mes Tiamou. Jucundus war wahnsinnig geworden, und von allen wurde das Gerücht verbreitet, seine Schwiegermutter Tatias habe ihm ein Gift gegeben; und Tatias stellte das Szepter auf und legte im Tempel Verwünschungen nieder...."

Tatias Fluch ist im Prinzip ein salvatorischer bzw. Unschuldseid - ein in der damaligen Rechtssprechung gängiges Verfahren. ${ }^{40}$ Sollte ihre Unschuldbeteuerung falsch sein, dann würde ihr Eid einem Meineid gleichkommen. Der Meineid war kein Vergehen, das die profane Justiz verfolgte; die Menschen erwarteten aber, dass die Götter - die angerufenen Zeugen bei der Eidesleistung und Rächer bei der Verfluchung - den Meineidigen bestrafen würden. Genau diese Strafe traf Tatias - davon waren ihre Mitbürger überzeugt -, als ihr Sohn ums Leben kam; dieses Familienunglück war für sie der Beweis, dass Tatias trotz ihres Schuldbewusstseins eine ungerechte Verfluchung vorgenommen hatte; die Mitglieder ihrer Familie mussten (nach ihrem Tod?) den Fluch rückgängig machen:

„... (Tatias) legte im Tempel Verwünschungen nieder, als ob sie Genugtuung gegen die Verleumdung gebe, obwohl sie sich (ihrer Unschuld) bewusst war. Aus diesem Grund haben die Götter sie mit einer Strafe bestraft, der sie nicht entkommen konnte. Auch ihr Sohn, Sokrates, als er am Eingang (des Tempelbezirks) vorbeiging, der zum Hain führt, mit einer Sichel in der Hand, mit der man Weinstöcke schneidet, ist diese auf sein Bein gefallen und so starb er durch eintägige Bestrafung. Groß nun die Götter von Azitta haben verlangt, dass das Szepter und die Verfluchungen, die im Tempel durchgeführt wurden, rückgängig gemacht werden. Und die Kinder von Jucundus und Moschion, die Enkel von Tatia, namentlich Sokrateia und Moschas und Jucundus und Menekrates, machten sie rückgängig, und stimm-

\footnotetext{
${ }^{39}$ Petzl 1994, Nr. 69; Versnel 2002, 64f.

${ }^{40}$ Chaniotis 1997, 372.
} 
ten die Götter für alles gnädig, und von nun an preisen wir die Götter, nachdem wir ihre Macht auf einer Stele aufgezeichnet haben".

Das soziologische Interesse des Textes ist unmittelbar evident. „Alle“ beobachteten Tatias' Handlungen, alle sprachen darüber. Unter diesem öffentlichen Druck in einer face-to-face-society, in einem kleinen Dorf, wo jeder jeden kannte, verlor Tatias das Gesicht. Ihr drohte die soziale Isolation; schlimmer noch: das Stigma der Hexe. Dies veranlasste sie, etwas zu unternehmen. Vermutlich kannte sie die Personen, die das Gerücht verbreitet hatten. In dieser Konfliktsituation mit ihren Nachbarn und Mitbürgern - nicht zuletzt aber auch mit ihrem Schwiegersohn und mit der eigenen Familie - gab es nur einen einzigen Weg, den Klatsch zu widerlegen und zu stoppen, der mit leiser Stimme ums Dorf ging: Umso lauter in einer öffentlichen Zeremonie, wieder unter den Augen „aller“, die Urheber der Verleumdung zu verfluchen. Dies war der Beweis ihrer Unschuld. Die Anwesenheit von Zuschauern und Zeugen war wichtig bei dieser Zeremonie, nicht nur als Form der sozialen Kontrolle ${ }^{41}$ - zumal in einer Magie-Klage -, sondern auch für die zu erwartende Manifestation der göttlichen Macht. Der wichtigste öffentliche Ort in Kula, an dem Tatias ihre Unschuld beteuern konnte, war wohl das Heiligtum.

Was könnte nun Tatias hiermit bewirken? Der Verleumder würde aus Angst vor dem Fluch veranlasst werden, ähnlich wie in Knidos (s.o.) die Verleumdung zurückzunehmen und der Frau Genugtuung geben; oder ein Unglück des Verleumders oder seiner Familie würde als seine gerechte Strafe gedeutet werden und der Klatsch gegen Tatias würde aufhören. Es kam anders. Wie in einer antiken Tragödie die eintägige Handlung zeigen soll, dass die Götter innerhalb eines Tages den mächtigsten Mann erniedrigen können, so vollzog sich auch in diesem Fall die Strafe innerhalb eines Tages und manifestierte die unfehlbare Gerechtigkeit und die Macht der Götter. Der Tod Tatias' und ihres Sohnes kam einem göttlichen Urteil gleich, das den Konflikt endgültig und unwiderruflich beendete. Tatias mag unschuldig gewesen sein; wichtig für die kleine Gemeinde war nur, dass sie jetzt ohne die Unsicherheit von Verleumdung und Klatsch konfliktfrei und in Harmonie mit den Überlebenden leben konnte.

Auch in diesem Text begegnen wird dem Ausdruck "das Szepter aufstellen“. Das Vergehen wurde in einer feierlichen Verfluchungszeremonie im Heiligtum der Götterjustiz übergeben. Es ist wohl davon auszugehen, dass auch das Niederlegen der Flüche im Tempel und ihr Löschen durch die Enkel Tatias' öffentliche Zeremonien waren.

Die Rolle der Öffentlichkeit tritt auch in einem Text, der einen Familienstreit betrifft, deutlich zum Vorschein (Nea Kome bei Kula, 146 n. Chr.): ${ }^{42}$

\footnotetext{
41 Versnel 2002.

42 Petzl 1994, Nr. 47.
} 
„Groß sind die Götter, die das Neue Dorf (Nea Kome) beherrschen. Im 231. Jahr. Menophila ärgerte sich über ihren Sohn, Polychronios, und machte ein Gelübde bei den Göttern, damit sie ihr Genugtuung geben. Und nachdem er bestraft worden war und die Götter gnädig gestimmt hatte, befahl ihr (der Gott), die Machtfülle der Götter aufzuzeichnen“.

Der Grund des Streites ist nicht bekannt, aber aus dem Hinweis auf Zorn und Genugtuung können wir erschließen, dass es auch hier primär um ein verletztes Ehrgefühl ging. Der Konflikt zwischen Mutter und Sohn konnte of: fenbar nicht innerhalb der Familie gelöst werden, und Menophila wandte sich an die Götter des Dorfes. Ein Unglück des Sohnes wurde von ihm als göttliche Strafe verstanden; durch nicht näher erläuterte Rituale (Opfer?, Weihung?, öffentliche Beichte?) versöhnte sich Polychronios mit den Göttern, vermutlich auch mit seiner Mutter. Die Tatsache, dass Menophila einen Befehl der Götter erhielt, diesen Vorfall auf einem Stein aufzuzeichnen und im Heiligtum aufzustellen, zeigt, dass die Priester über diesen Streit (von ihr?) informiert waren. Man denkt natürlich an das Einreichen eines Pittakion, wie im Falle des um seine Ehre verletzten Artemidoros (S. 242) oder der anonymen Frau, die Opfer von Diebstahl geworden war (S. 244). Schauen wir uns letzteren Text noch einmal an:

„Ich weihe der Mutter der Götter alle goldenen Sachen, die ich verloren habe, damit sie sie sucht und alles offenbart und jene bestraft, die sie haben, gemäß ihrer eigenen Machtfülle, damit sie nicht belächelt wird“.

Auch hier ist die Rolle der Öffentlichkeit deutlich. Der Dieb (oder die Diebin) sollte bekannt werden (wortwörtlich: „in die Mitte gebracht werden“) und die Leute sollten nicht über die Unfähigkeit der Göttin lachen, die gestohlenen Sachen ausfindig zu machen. Noch deutlicher als im Falle der Tatias und des Artemidoros war die Verfasserin dieses Textes primär um ihre Ehre besorgt. Der Diebstahl bedeutete nicht nur den Verlust von Wertsachen, sondern auch von Ansehen, denn jemand freute sich über ihr Unglück - diesem Moment der Schadenfreude begegnen wir auch in einem anderen Text. Aus diesem Grund wollte die anonyme Frau Rache.

Ihrè Handlung konnte eigentlich nur dann wirksam sein, wenn der Dieb wusste, dass er nun göttliches Eigentum besaß, dadurch ein Sakrileg begangen hatte und von der zornigen Göttin verfolgt wurde. Die Wirksamkeit des Pittakion setzt seine Publizität voraus; seine Verfasserin rechnet mit der Existenz von Zuschauern, die einfach abwarten, über wen sie lachen sollten: den bestraften Dieb, sein Opfer oder die untätige Göttin.

Die Konflikte, denen wir in diesen Texten begegnen, sind vor dem Hintergrund der Rolle von Ehre und Schande in kleinen Gemeinden zu deuten. Das Ende des Konfliktes ging mit der Wiederherstellung der Ehre der geschädigten Person einher, und dies erklärt die Rolle der Öffentlichkeit. 


\title{
6 Öffentlichkeit und Effektivität der Götterjustiz
}

Ein Text aus dem Dorf Tazenon katoikia (210 n. Chr.) berichtet von einer anderen Konfliktsituation als bei den bisher zitierten Texten. Er bezeugt die öffentliche Verfluchung von Straftätern durch eine Gemeinde; das Delikt war Einbruch in das Haus zweier Vollwaisen, Diebstahl von Dokumenten und anderen Sachen und heimtückisches sowie böswilliges Handeln (der dolus des römischen Strafrechtes): ${ }^{43}$

\begin{abstract}
„Dem Mes Petraites und dem Mes Labanas. Als Metrophanes und Flavianus, Söhne des Philippikos, von ihren Eltern als Waisenkinder allein gelassen wurden und einige Menschen aus dem Dorf ihnen nachstellten und von ihrem Haus heimlich Urkunden und andere Sachen nahmen und die Waisen von Gläubigern hinweggerissen wurden, hat das Dorf der Tazenoi dies missbilligt und das Szepter aufgestellt gegen diejenigen, die den bösen Anschlag gegen sie verübt hatten. Und der Gott verfolgte sie und bestrafte sie und tötete die Menschen, die Böses gegen sie im Sinne hatten. Der Gott verlangte nun, dies auf eine Stele aufzuzeichnen und seine Macht zu preisen, weil ... [der Rest des Textes ist nicht erhalten]“.
\end{abstract}

In diesem Fall sah sich eine ganze Gemeinde mit einer unfassbaren Ungerechtigkeit konfrontiert. Einige Personen waren auf illegalem Weg in Besitz von Urkunden (wohl Hypotheken) gekommen und nutzten sie gegen zwei Vollwaisen. Die gesamte Gemeinde war empört, aber hatte offenbar keine anderen Mittel, gegen diese Ungerechtigkeit einzugreifen, als die feierliche Verfluchung der Täter. Die öffentliche Zeremonie diente dazu, die Schurken darüber zu informieren, dass sie von den Göttern verfolgt wurden. Dennoch kamen sie nicht zur Vernunft: Ihr Tod wurde als Strafe aufgefasst - und verriet eindeutig ihre Identität.

Ein anderer Straftäter war einsichtiger. Eine Gemeinde hatte alle, die Kleider von einem öffentlichen Bad stehlen würden, prophylaktisch verflucht: ${ }^{44}$

„Groß ist Mes Axiottenos, König in Tarsi. Weil das Szepter aufgestellt wurde, wenn jemand etwas vom Bad stiehlt ....

Ein Dieb missachtete diese Warnung, aber gerade wegen der Kenntnis der Verfluchung sah er sich später dazu gezwungen, das gestohlene Gut an das Heiligtum zurückzubringen:

„... Als nun ein Kleidungsstück gestohlen wurde, bestrafte der Gott den Dieb und führte ihn nach einiger Zeit dazu, das Kleidungsstück zum Gott zu bringen und (die Tat) zu gestehen. Der Gott befahl nun durch einen Engel, das Kleidungsstück zu verkaufen und seine Macht in einer Inschrift zu schildern. Im 249. Jahr. ${ }^{*}$

Das Kleidungsstück wurde nicht an seinen Besitzer zurückerstattet, sondern verkauft; der Erlös ging gewiss an die Kasse des Heiligtums, vermutlich

43 Petzl 1994, Nr. 35; Versnel 1999, $131 f$.

${ }^{44}$ Petzl 1994, Nr. 3. 
weil das Opfer des Diebstahls sein gestohlenes Eigentum dem Gott überlassen hatte.

Die kurze Vorstellung einer kleinen Auswahl epigraphischer Zeugnisse von Alltagskonflikten erlaubt, einige gemeinsame Merkmale zu erkennen. Ihre Protagonisten waren die Bewohner meist kleiner Dörfer in Kleinasien. Sie waren die Opfer von Unrecht - oder sie glaubten es: von Verleumdung, Betrug, Diebstahl, Nicht-Erstattung eines Darlehens. In einigen Fällen wussten sie, wer der Täter war, in anderen nicht. Keiner dieser Texte erwähnt eine Meldung an profane Behörden - sie ist aber nicht auszuschließen (absence of evidence is not evidence of absence). Oft ging es nicht primär um materiellen Verlust, sondern um Gesichtsverlust. Folglich erhofften die Opfer nicht die Rückgabe von Eigentum, sondern Rache, die öffentliche Erniedrigung der Täter. Diese Motive treten in vier Texten, die nicht zur Gattung der Beichtinschriften gehören, besonders deutlich hervor. Der erste Text ist ein „Gebet für Gerechtigkeit" aus Knidos, die Klagen einer frustrierten - vielleicht streitsüchtigen oder unter leichten Verfolgungswahn leidenden - Frau: ${ }^{45}$

„Ich deponiere im Heiligtum der Demeter und der Kore denjenigen, der gegen mich behauptet hat, ich bereite Gifte gegen meinen Mann. Er möge innerlich brennend mit allen seinen Angehörigen zu Demeter hinaufsteigen und beichten, und nicht mögen ihm zuteil werden eine leicht versöhnliche Demeter und Kore und nicht die Götter, die bei Demeter sind. Für mich aber soll es recht und gut und frei sein, mit ihm - meinem Mann - unter einem Dach zu leben und ihn auf jede nur mögliche Weise zu umarmen.

Ich deponiere im Heiligtum der Demeter auch denjenigen, der die schriftliche Klage gegen mich eingereicht oder dies aufgetragen hat; nicht mögen ihm zuteil werden eine leicht versöhnliche Demeter und Kore und nicht die Götter bei Demeter, sondern er möge innerlich brennend mit allen Seinigen zu Demeter hinaufsteigen.

Ich, Hagemone, deponiere den Armreif, den ich in den Gärten des Rhodokles verloren habe, im Heiligtum der Demeter und der Kore und aller Götter und Göttinnen. Wenn der Finder ihn wieder zurückgibt und dafür den Finderlohn erhält, dann möge alles recht und gut und frei sein für mich, die ich den Armreif wiederbekomme, und für ihn, der ihn zurückgibt. Wenn er ihn aber nicht zurückgibt, dann mögen ihm ungnädig sein Demeter und Kore und alle Götter und Göttinnen bei Demeter und Kore, und wenn der Armreif gar verkauft ist, dann soll ihn das schlechte Gewissen von Demeter und Kore quälen. Ich deponiere im Heiligtum der Demeter und der Kore auch denjenigen, dem ich mehr bezahlt habe über das Gewicht hinaus, das ich verlangt hatte. Herrin, für mich möge alles recht und gut sein.

Ich deponiere im Heiligtum der Demeter und der Kore auch denjenigen, der mein Haus in Unfrieden bringt, ihn und alles Seinige; für mich aber möge alles recht und gut und frei sein, in jeder Weise".

Hegemone lebte im Streit mit ihrer Umgebung: mit ihrem Mann und ihrer Familie, weil sie der Magie verdächtigt wurde; mit ihren Nachbarn, die schriftliche Klagen gegen sie eingereicht hatten; mit dem unbekannten Finder des Schmuckes, den sie verloren hatte; mit dem Hersteller und Verkäufer einer Schmucksache, den sie des Betrugs beschuldigte. Ihren Frieden hoffte sie

45 Blümel 1992, Nr. 150; vgl. Versnel 1991, 72-75, und 1994. 
dadurch zu erreichen, dass sie einen umso erbitterten Konflikt zwischen ihren Widersachern und den Göttern provozierte, den Konflikt von der Welt der Sterblichen auf die Welt der Götter verlagerte. Die gleiche Strategie verwendete auch der Verfasser eines Bindezaubers gegen seine Widersacher in Amorgos: ${ }^{46}$

„Herrin, Demeter, Königin, zu deinen Füßen falle ich, dein Sklave. Ein gewisser Epaphroditos hat meine Sklaven angenommen, er hat sie falsch instruiert, er hat ihnen Ideen gegeben, er hat sie beraten, er hat sie verdorben, er zeigte Schadenfreude, er hat sie beflügelt (ermutigt), er hat ihnen die Idee gegeben, wegzulaufen, er hat meine junge Sklavin verführt, um sie sich, gegen meinen Willen, zur Frau zu nehmen. Aus diesem Grund ist sie zusammen mit den anderen (Sklaven) weggelaufen. Herrin, Demeter, ich, der all das erleiden musste und keine andere Unterstützung habe, wende mich an dich, damit du mit mir Erbarmen zeigst, so dass ich mein Recht finde. Veranlasse, dass jener, der sich so mir gegenüber verhalten hat, keine Befriedigung/keinen Erfolg hat, weder beim Stehen noch beim Gehen, weder im Körper noch im Sinne; ihm sollen weder die Sklaven noch die Sklavinnen dienen, weder jung noch alt. Setzt er ein Plan um, soll er ihn nicht durchführen können. Möge dieser Bindezauber seinen Haushalt ergreifen. Niemals soll er das Weinen eines Kindes hören, niemals soll er einen Tisch der Freude decken. Weder Hund soll bellen, noch Hahn krähen. Sät er, so soll er dann nicht ernten; weder Erde noch Meer sollen ihm Früchte tragen. Er soll keine Freude kennen, sondern sowohl er als auch seine ganze Habe in übler Weise vernichtet werden“.

Der Autor dieses Textes, gekränkt durch die Schadenfreude seines Gegners, in seiner Ehre verletzt, wollte nicht Wiedergutmachung, sondern Rache. Dass er sich an eine Göttin wandte, bedeutet nicht unbedingt, dass er nicht auch eine Klage wegen seiner entlaufenen Sklaven eingereicht hatte.

Andere Personen wandten sich an profane Behörden in solchen Situationen, wie der Jude Andronikos nach einem Streit (Herakleopolites in Ägypten, 135 v. Chr.): ${ }^{47}$

„An den Politarchen Alexandros und das Politeuma (die jüdische Gemeinde) von Andronikos, einem Angehörigen des Politeuma. Am 13. des gegenwärtigen Monats fing Nikarchos, zugehörig zu den Hafenbewohnern, absichtlich auf der Straße einen Streit an. Er beschimpfte mich lange und unziemlich, dann beschuldigte er mich auch grundlos in Anwesenheit einiger Personen, sowohl von Mitgliedern des Politeuma (also Juden) als auch von Nichtjuden. Daher bitte ich, ihn vorzuladen und eine Entscheidung gegen ihn zu treffen“.

Die besonderen Umstände des Streites fallen sofort auf: Es geht nicht allein um grundlose Beschimpfung - der Grund des Streites wird nicht einmal genannt; es geht darum, dass Andronikos auf der Straße, also in der Öffentlichkeit, beschimpft wurde; schlimmer noch: in Anwesenheit der eigenen Leute und von Fremden.

Die Bedeutung von Ehre als Ursache von Konflikten - ein weit verbreitetes Phänomen, das auch die vorhin zitierten Texte aus Amorgos und Ägypten ex-

46 Inscriptiones Graecae XII 7, 1; Versnel 1999.

17 Cowey/Maresch 2001, 35-39 Nr. 1. 
emplifizieren - ist einer der Schlüssel für das Verständnis der Götterjustiz. Der Angst vor der eigenen Erniedrigung - und der Hoffnung auf Erniedrigung des Gegners - verdanken wir also die Existenz der Beichtinschriften und der relevanten Texte. Sie waren an die Öffentlichkeit gerichtet, auf nicht vergänglichem Material aufgezeichnet, öffentlich aufgestellt. Das Heiligtum war der privilegierte öffentliche Raum, die Götter die unfehlbaren Vollstrecker der Strafe. Der Glaube, dass das Gebet für Gerechtigkeit effektiv war, beruhte ausschließlich auf den schriftlichen Berichten vollzogener Strafen, auf den Beichten jener, die bereits bestraft worden waren, auf den dankbaren Weihungen jener, deren Wünsche in Erfüllung gegangen waren. Aus diesem Grund verlangten die Priester die Aufstellung der Inschriften.

Gerade in diesen Orten waren die Götter die nächsten Vertreter einer administrativen Gewalt. Die einfachen Menschen, die häufig vom Tempel in der einen oder anderen Form abhängig waren (als Tempelsklaven, Sklaven und Freigelassene der Priester, Pächter des heiligen Landes, Mieter von Häusern, die dem Tempel gehörten, Schuldner der Tempelbank), wandten sich an die Götter, um eine gute Ernte zu wünschen, das Heil ihrer Tiere, die Heilung von Krankheit, gesunden Nachwuchs, eine gute Heirat. Die Tempel waren für sie Banken, Arbeitgeber, Krankenhäuser und offenbar auch Ansprechpartner in den Fragen des täglichen Rechtes.

Als ich mich vor zehn Jahren zum ersten Mal mit diesem Thema befasste, war ich von der Arbeitshypothese ausgegangen, die Tempeljustiz in Lydien und Phrygien lasse sich aus einer Krise der römischen Verwaltung erklären, die die relativ abgelegenen und durch Bergketten von den großen Verwaltungszentren isolierten Gegenden besonders stark traf. Diese Annahme ließ sich nicht bestätigen, nicht zuletzt, weil die literarischen und juristischen Quellen uns für die Frage, wie effektiv die römische Verwaltung im Bereich der Rechtssprechung war, im Stich lassen. Wir kennen die Menschen, die sich an den Tempel wandten, um Recht und Genugtuung zu finden, weil sie diese Angelegenheiten auf Inschriften schilderten. Wir werden aber nie erfahren, wie viele ihrer Landsleute sich doch an den Komarchos, den Eirenarches, die Magistrate der nächsten Stadt, den Statthalter wandten, weil uns andere Quellen (vor allem die Papyri) fehlen. Es besteht die Gefahr, Verwaltungslücken dort zu sehen, wo es vielleicht nur Quellenlücken gibt.

Leider können wir auch in diesem Punkt nur mit Indizien operieren. Es lässt sich zunächst einmal ein gewisses Misstrauen gegenüber den römischen Behörden spüren. Schwer fiel auch das Fehlen einer effektiven polizeilichen Gewalt ins Gewicht, das die Opfer von Straftaten oft auf sich gestellt sein ließ. Die ständige Zunahme von Verwünschungen gegen Grabschänder in Kleinasien, vor allem im 3. Jh., verrät die Überzeugung, dass nur der Gott effektiv bestrafen und beschützen konnte. Der Kult von Gottheiten, die Gerechtigkeit und Verfolgung der Verbrecher personifizieren, verbreitet sich in derselben Zeit: Dikaiosyne (Gerechtigkeit), das Götterpaar Hosion kai Dikaion (Recht 
und Frömmigkeit), Nemesis (Göttin der Strafe), Helios Pantepoptes (die alles sehende Sonne), Dikes Ophthalmos (das Auge der Gerechtigkeit), Mes Dikaios (der gerechte Mes). ${ }^{48}$ Die Überzeugung, dass der Gott früher oder später den Ungerechten bestraft, wird sehr prägnant in einer Grabinschrift aus Iulia Gordos formuliert:49 „Es gibt eine Göttin der Strafe; also beachte die Gerechtigkeit“. Das sichere Wissen von der göttlichen Strafe setzt jedoch die schmerzliche Erfahrung voraus, dass der Mensch gegenüber der Ungerechtigkeit oft machtlos ist.

Diese Indizien reichen jedoch nicht aus, um die Götterjustiz aus einer schwachen Verwaltung zu erklären. Nicht in der Ohnmacht der römischen Verwaltung, sondern in der Macht der Tempel in den kleinen dörflichen Gemeinden und in der Wirkungsmacht von verletzten Ehrgefühlen in kleinräumigen face-to-face-Gemeinden haben wir die Erklärung für die Götterjustiz zu suchen. Die Priester traten als Beschützer von Normen, Recht und Ordnung auf. Ihr einziges Mittel, der Fluch, erscheint vielleicht uns aufgeklärten Zeitgenossen weniger wirksam als er tatsächlich war. Denn durch die feierliche, öffentliche Verfluchung erfuhr der Straftäter, dass die Götter ihn verfolgten, und wurde veranlasst, den Tempel aufzusuchen, um seine Tat zu gestehen und die Sache wieder gutzumachen wie z. B. der Kleiderdieb im vorhin zitierten Text oder aber um seine Unschuld zu beteuern (wenn er glaubte, dass der Fluch unberechtigt war).

Dieses Mittel war deswegen wirksam, weil die gewöhnlichen, kleinen oder großen Schäden des Alltags als Strafe der Götter aufgefasst wurden. Es war nur eine Frage der Zeit, bis dem Urheber eines Konfliktes tatsächlich etwas zustieß. Wenn eine Sichel auf das Bein fiel, ein Esel oder ein Familienmitglied starb, die Ernte schlecht war, eine Erkrankung eintrat, eine (unverheiratete) Tochter ihre Jungfräulichkeit verlor, wusste er, dass eine Verfehlung zu gestehen und zu sühnen war. Manchmal bedurfte es etwas Mühe, bis er den Weg zum Geständnis fand. Aber dann, wenn wiederholte Schäden seine Unnachgiebigkeit doch brachen, wuchs der Glauben der einfachen Menschen an die göttliche Strafe umso mehr. Wir verstehen jetzt auch die Existenzberechtigung der Sühneinschriften: Sie waren der Beweis für die Effektivität der Götterjustiz.

Es wäre jedoch verfehlt, die Götterjustiz als Folge einer konsequenten Verdummung der einfachen Menschen zu sehen. Die Tempel waren in dieser Zeit die Bewahrer einer strengen moralischen Ordnung und Vermittler von Verhaltensnormen in abgelegenen Gebieten. Die Sühneinschriften enthalten nicht nur harte, oft sinnlos erscheinende Strafen, sondern auch moralische Lehren, die Gebote des Gottes. ${ }^{\circ}$ In einigen Fällen hören wir von harter Be-

\footnotetext{
${ }_{48}$ Versnel 1991, 7of. mit Anm. 44-47; Ricl 1991, 1992a, 1992b; Petzl 1998; Chaniotis 2004, 1of.

49 Supplementum Epigraphicum Graecum XXX 1480.

so Chaniotis 1997, 376f.
} 
strafung - sogar mit dem Tod - für anscheinend lächerliche Verletzungen von Kultregelungen. Dabei ging es allerdings nicht um die konkrete Tat, sondern um die Verletzung der Normen. Wenn eine Frau mit beflecktem Kleid den Tempel betrat und ein Mann Fleisch von nicht geopferten Ziegen aß, demonstrierten diese Personen durch den Bruch der Ritualvorschrift einen Mangel an Bereitschaft, Normen zu respektieren und die Macht der Götter zu achten. Sie verletzten die Ehre der Götter.

Das gemeinsame Merkmal dieser Texte - Beichtinschriften, Gebete für Gerechtigkeit, Gelübde, Grabinschriften mit Bitten um Rache - besteht darin, dass die Bestrafung eines Urhebers von Ungerechtigkeit, der der Justiz der Sterblichen entkommen war, den Göttern überlassen wurde. Es ging also um ungelöste Konflikte unter den Sterblichen, die nun der Strafe der Unsterblichen unterlagen. Ein weiteres gemeinsames Merkmal vieler Texte war die Rolle von Ehre, Schande und Gesichtsverlust. Meine Ausführungen haben hoffentlich gezeigt, dass die Opfer der Ungerechtigkeit eine besondere Überzeugungsstrategie anwandten, um die Götter auf ihren ungelösten Konflikt aufmerksam zu machen: Sie übertrugen den Konflikt auf die Götter, sie machten die Götter nicht zu Richtern, sondern zur Konfliktpartei.

Ich zitiere eine von Bertolt Brechts Geschichten vom Herrn Keuner: „Einer fragte Herrn K., ob es einen Gott gäbe. Herr K. sagte: ,Ich rate dir, nachzudenken, ob dein Verhalten, je nach der Antwort auf diese Frage sich ändern würde. Würde es sich nicht ändern, dann könnten wir die Frage fallenlassen. Würde es sich ändern, dann kann ich dir wenigstens noch so weit behilflich sein, dass ich dir sage, du hast dich schon entschieden: Du brauchst einen Gott ${ }^{\text {'“. Es }}$ gab viele Gründe, warum die Leute der anatolischen Dörfer Götter dringend brauchten.

\section{Literatur}

Blümel W (1992) Die Inschriften von Knidos. I. Bonn: Habelt

Burkert W (1996) Creation of the Sacred. Tracks of Biology in Early Religions. Cambridge, Mass.: Harvard University Press

Chaniotis A (1997) Tempeljustiz im kaiserzeitlichen Kleinasien: Rechtliche Aspekte der Beichtinschriften. In: Thür G, Vélissaropoulos-Karakostas J (Hrsg.) Symposion 1995. Vorträge zur griechischen und hellenistischen Rechtsgeschichte (Korfu, 1.-5.September 1995). Köln et al., 353-384

Chaniotis A (2004) Under the Watchful Eyes of the Gods: Aspects of Divine Justice in Hellenistic and Roman Asia Minor. In: S. Colvin (Hrsg.), The Greco-Roman East. Politics, Culture, Society (Yale Classical Studies 31). Cambridge, 1-43

Cowey JMS, Maresch K (2001) Urkunden des Politeuma der Juden von Herakleopolis (144/3-133/2 v. Chr.). Wiesbaden: Westdeutscher Verlag

Eger O (1939) Eid und Fluch in den maionischen und phrygischen Sühneinschiften. In: Festschrift Paul Koschaker III, Weimar, 281-293

Graf F (1996) Gottesnähe und Schadenzauber. Die Magie in der griechisch-römischen Antike. München: Beck 
Klauck H-J (1996) Die kleinasiatischen Beichtinschriften und das Neue Testament. In: Cancik H. u. a. (Hrsg.) Geschichte - Tradition - Reflexion. Festschrift für Martin Hengel zum 70. Geburtstag III, Tübingen, 63-87

Lloyd-Jones $H$ (1983) The Justice of Zeus. Berkeley et al.: University of California Press

Parker R (1983) Miasma. Pollution and Purification in Early Greek Religion. Oxford: Oxford University Press

Petzl G (1988) Sünde, Strafe, Wiedergutmachung. In: Epigraphica Anatolica 12:155-166

Petzl G (1994) Die Beichtinschriften Westkleinasiens (Epigraphica Anatolica 22). Bonn: Habelt

Petzl G (1997) Neue Inschriften aus Lydien (II). Addenda und Corrigenda zu „Die Beichtinschriften Westkleinasiens". In: Epigraphica Anatolica 28:69-79

Petzl G (1998) Die Beichtinschriften im römischen Kleinasien und der Fromme und Gerechte Gott. Opladen: Westdeutscher Verlag

Ricl M (1991) Hosios kai Dikaios. Premiere partie: Catalogue des inscriptions. In: Epigraphica Anatolica $18: 1-70$

Ricl M (1992a) Hosios kai Dikaios. Seconde partie: Analyse. In: Epigraphica Anatolica 19: 71-102

Ricl M (1992b) Hosios kai Dikaios. Nouvaux monuments. In: Epigraphica Anatolica 20:95-100

Ricl M (1995) The Appeal to Divine Justice in the Lydian Confession-Inscriptions. In: Schwerrheim E (Hrsg.) Forschungen in Lydien (Asia Minor Studien 17). Bonn, 67-76

Robert L (1983) Documents d'Asie Mineure. In: Bulletin de Correspondance Hellénique 107: 497-599

Sokolowski F (1955) Lois sacrées de l'Asie Mineure. Paris: De Boccard

Sourvinou-Inwood C (1995) Reading Greek Death to the End of the Classical Period. Oxford: Oxford University Press

Strubbe JHM (1991) „Cursed Be He That Moves My Bones“. In: Faraone CA, Obbink D (Hrsg.) Magika Hiera: Ancient Greek Magic and Religion, New York/Oxford, 33-59

Varinlioğlu E (1991) Vier Inschriften aus Lydien. In: Epigraphica Anatolica 18 : $91-94$

Versnel HS (1991) Beyond Cursing: The Appeal to Justice in Judicial Prayers. In: Faraone CA, Obbink D (Hrsg.) Magika Hiera: Ancient Greek Magic and Religion, New York/Oxford, 60-106

Versnel HS (1994) Pepremenos. The Cnidian Curse Tablets and Ordeal by Fire. In: Hägg R (Hrsg.) Ancient Greek Cult Practice from the Epigraphical Evidence, Stockholm, 145-154

Versnel HS (1999) Punish Those Who Rejoice in Our Misery: On Curse Texts and Schadenfreude, in Jordan DR et al. (Hrsg) The World of Ancient Magic, Bergen, 125-162

Versnel HS (2002) Writing Mortals and Reading Gods. Appeal to the Gods as a Dual Strategy in Social Control. In: Cohen D (Hrsg.) Demokratie, Recht und soziale Kontrolle im klassischen Athen, München, 37-76

Zingerle J (1926) Heiliges Recht. In: Jahrbuch des Österreichischen Archäologischen Instituts 23 (Beiblatt) :5-72 